\title{
Examining User Experience of Moodle e-Learning System
}

\author{
Layla Hasan \\ School of Computing, Faculty of Engineering \\ Universiti Teknologi Malaysia, Johor, Malaysia
}

\begin{abstract}
This research investigates the user experience (UX) of the Moodle e-learning system employed at one university in Malaysia from students' perspectives. Comprehensive user experience (UX) criteria were suggested, which was adopted from two reliable criteria, to evaluate the user experience (UX) of the e-learning system. The suggested comprehensive user experience (UX) criteria consist of 8 categories and 29 corresponding subcategories; these can be used to evaluate teaching and learning, usability, and hedonic aspects of an e-learning system. Semistructured interviews and questionnaires were employed based on the suggested user experience (UX) criteria to collect qualitative and quantitative data regarding users' experience (UX) of the tested e-learning system. The results showed that the e-learning system had positive user experience (UX) in general from the students' perspectives. The results also showed that the students were satisfied with most of the metrics related to teaching and learning, usability and hedonic. However, the students identified some challenges they faced while interacting with the e-learning system which could be improved in order to improve their user experience (UX) and gain more benefits from a good user experience (UX) e-learning system.
\end{abstract}

Keywords-User Experience (UX); e-learning system; Moodle; usability; learning management system

\section{INTRODUCTION}

The importance of e-learning is well recognized globally due to the continuous advancement in information technology and the rise of Internet adoption worldwide. The COVID-19 pandemic has increased the importance of e-learning as it has facilitated education in proceeding worldwide during the lockdown [1]. e-Learning is defined as: "Education that uses computerized communication systems as an environment for communication, exchange of information and interaction between students and instructors" [2]. The e-learning market is growing rapidly worldwide; it is expected that it will reach $\$ 336.98$ billion by 2026 [3].

e-Learning is conducted based on learning management systems which are related to software systems that support the management of educational courses, either in the traditional face-to-face classroom courses or in blended or distance education $[4,5]$. The use of learning management systems improves the quality of teaching, facilitates access to educational materials, and supports synchronous and asynchronous interactions between staff and students [6].

Learning management systems can be categorized in terms of their fees into: commercial software systems which have high license fees (such as Blackboard), or free, open-source software systems (such as Moodle) [7]. Moodle is one of the most common learning management systems that is employed worldwide in academic institutions due to its robustness, security and affordability [8]. The Moodle e-learning system provides various functions and tools that lecturers can employ to enrich and support the learning experience. These include: uploading instructional materials; displaying marks and feedback; conducting online quizzes and tests; supporting communications using messages; supporting group chats and online meetings; uploading advertisements and news; and sending alerts to students as a reminder to submit materials [9].

As the employment of e-learning management systems increases globally, and since most students depend on them in their learning processes, it is important to ensure that these systems are accepted, understood and used properly by the students. One of the ways to increase the acceptance and usage of these systems is to ensure that they are free from user experience (UX) and usability problems [6]. The success of elearning is highly dependent on the users' experience and perceptions towards such systems [10].

The user experience (UX) can be defined as: “A person's perceptions and responses resulting from the use and/or anticipated use of a product, system or service. It includes all the user's emotions, beliefs, preferences, perceptions, physical and psychological responses, behaviours and accomplishments that occur before, during and after use" [11]. However, usability is defined as related to "the extent to which a system, product or service can be used by specified users to achieve specified goals with effectiveness, efficiency and satisfaction in a specified context of use" [12]. Alternatively, Maslov et al. [10] provided a definition of the UX of e-learning system as: "inherently a fuzzy, multi-faceted, context-dependent and dynamic concept covering all aspects how end-users experience, behave, perceive, feel and think about an elearning system and how they reflect on the use, anticipation of the use and use it in order to attain hedonic and/or functional value of e-learning".

It is agreed that usability can be used to evaluate aspects of user experience [11]. According to Bevan [13], usability employs quantitative methods to evaluate the use of an interface objectively and pragmatically with the goal of optimizing users' performance. The UX, however, is more subjective and hedonic and has the goal of optimizing users' satisfaction by achieving both pragmatic and hedonic goals [13]. Hassenzahl et al. [14] also describes the two types of aspect which the UX considers. These are related to: 
pragmatic aspects (e.g., traditional usability features); and hedonic aspects (e.g., emotional responses).

UX and usability are critical quality factors in e-learning systems and the learning process [15]. A good UX e-learning system means that the system is usable, pleasurable, satisfactory, and attractive to the learners [14, 16]. It is important to ensure that the e-learning system provides positive UX to the learners as UX affects users' acceptance, understanding, efficiency and satisfaction while using the system [6]. This will therefore facilitate and enrich the learning process.

The Moodle e-learning system is used and customized by its local experts for each academic institution based on the institution's local context due to a general lack of UX and usability experts. This often results in an instance of Moodle which has usability and UX problems [6]. The literature showed that there are many research studies which have evaluated the usability of Moodle learning management systems employed in various academic institutions and the results of these studies have shown several usability problems [for example, 7, 17-21]. However, user experience (UX) is still a novel research area; there is lack of a specific UX technique or UX criteria that could be used to evaluate the UX of e-learning systems and there is also a lack of research which investigates the user experience (UX) of Moodle elearning system from the perspectives of students [6].

The aim of this research is to examine the user experience (UX) of the Moodle e-learning system at the University of Technology Malaysia (UTM) from the perspectives of students. In order to examine the UX, comprehensive criteria were developed based on two reliable criteria [5, 22]. The results of this research uncover the current UX of the Moodle e-learning system used by the University of Technology Malaysia from the perspectives of the students and presents both the current challenges and suggested improvements to the e-learning system. The proposed approach (suggested criteria) employed in this research can be used to: evaluate comprehensively the user experience (UX) of an e-learning system, and increase the acceptance, satisfaction, efficiency and usage of e-learning systems from students' perspectives. Also, the results of this research could contribute towards increasing research and awareness on user experience (UX) of e-learning systems.

This research is divided into six sections. Section 2 presents earlier research which has evaluated the UX of elearning systems. The methodology is presented in Section 3. Section 4 presents the results while Section 5 presents the discussion. Finally, in Section 6, the conclusion is presented.

\section{LITERATURE REVIEW}

Researchers indicated that the concept of UX is subjective and holistic and therefore there are no specific UX metrics to evaluate UX of e-learning systems [6, 15, 23, 24]. Some researchers have suggested models including UX metrics to evaluate UX for e-learning systems, while others have used existing proposed metrics to evaluate such systems. For example, Topolewski et al. [22] proposed a UX model which describes user experience in terms of 21 properties related to five categories that influence users' intention to use elearning. The model was tested empirically by designing a survey which consisted of the identified UX properties. The survey was given to students who used a specific mobile application (Jaxber app) to evaluate their UX experience with this e-learning system. The results proved the reliability and validity of the proposed model; some properties were deleted so that the model finally consisted of 18 UX properties which can be used to evaluate the UX of e-learning systems.

Maslov et al. [10] also explored user experience of the Moodle learning management system from the perspectives of students at one university using semi-structured interviews and a survey, which was designed based on the UX model of Topolewski et al. [22]. The results showed that Moodle was perceived as a useful and productive platform for learning because it provided all relevant information, such as course information and course materials, in the same place. It also supported the sending of assignments and managing the percentage of the course's completion. The results showed also that most of the students considered Moodle as an easyto-use platform. However, for other students, Moodle was perceived as a hard platform to navigate and use but one which became easier to use over time and experience. Furthermore, the results indicated that Moodle was meaningful and engaging, although this depended on the teacher, the course content and how simply it was structured. The challenges the students faced on Moodle during their interactions with it included: slow loading of documents in a browser window; lack of support for group work; it was not entertaining or novel, and the interface was not attractive; technical issues existed (for example, server downtime, website inaccessibility, login issues); courses were sometimes badly structured; weak communication; lack of customization of the front page; and the lack of a mobile application.

Alternatively, Mtebe [6] identified the factors that influenced the UX of Moodle e-learning systems implemented in two universities in Tanzania using a questionnaire consisting of Nielsen heuristics which focused on usability; didactic metrics, which focused on teaching and learning; and hedonic metrics, consisting of three criteria (stimulation, identification, and evocation) adopted from three resources [5, $25,26]$. Focus groups were then used for further discussions with the students. The results showed that the e-learning systems of both universities had a large number of usability and UX problems. Examples of usability problems included: lack of help and documentation features; and inconsistency in colors and layouts (the organization of instructional materials differed from one course to another). The results also showed also that the e-learning systems had several UX problems related to instructor skills and usage although these were not associated directly with the UX of the system being used. These included: the systems had outdated instructional materials while some courses did not have sufficient materials of this type; many instructors were unable to use the elearning system effectively and therefore ended up using only very few features of the systems. Finally, the results showed that the adoption and use of e-learning systems evoked, for students, positive feelings and memories of their learning activities; the students also perceived the use of the e-learning 
systems communicated advantageous identities to other students and their instructors. However, the students were neutral as to whether the use of e-learning systems was interesting or had exciting functionalities, content, presentation and interaction style.

Furthermore, Nakamura et al. [16] used two UX evaluation techniques (UEQ and IEAM) to evaluate the Edmodo learning management system from the perspective of 34 students at the Federal University of Amazonas. The results from the UX evaluation of Edmodo showed that, despite the fact that students faced some difficulties during the use of the Edmodo, its UX was perceived as positive. The students found the elearning system easy to use, useful and attractive. Examples of the challenges faced by the students included: too much time spent searching for the learning materials and a lack of understanding regarding how to perform the matching quiz correctly. The results also showed that the e-learning system did not motivate them. Adding more interesting features was suggested to increase students' engagement with learning. However, around $41 \%$ of the students reported that they were not able to fully evaluate their UX using the techniques (UEQ and IEAM), indicating a need for improvement.

\section{METHODOLOGY}

Earlier research indicated that no specific UX evaluation technique has been developed to evaluate the UX of elearning. Therefore, this research suggested UX evaluation criteria adopted from two reliable criteria: instructional or didactic criteria, which focus on teaching and learning (adopted from Mtebe and Kissak [5]); and UX criteria, which focus on both usability and hedonic metrics (adopted from Topolewski et al., [22]). Research proved the reliability of the UX criteria which were developed by Topolewski et al. [22] as a technique which can be used to evaluate the UX of elearning systems [10, 22]. However, these UX criteria focus on hedonic metrics and do not include specific metrics to evaluate the quality of the teaching and learning experience using e-learning systems. For this, the instructional or didactic criteria developed by Mtebe and Kissaka [5] were used to complement the UX criteria developed by Topolewski et al. [22] to evaluate comprehensively the UX of the e-learning system in terms of teaching and learning, usability and hedonic metrics. The suggested UX criteria consist of 8 categories and 29 corresponding sub-categories. Table I shows the categories and sub-categories of the suggested UX criteria while Appendix I presents the categories, sub-categories and the descriptions of the suggested UX criteria. Table II shows a comparison between the suggested UX criteria employed in this research with the other similar UX criteria employed by earlier research.

In order to evaluate the user experience (UX) of the UTM university from the students' perspectives using the suggested criteria, qualitative and quantitative methods were considered. For qualitative data, semi-structured interviews were conducted based of the suggested UX criteria categories and sub-categories as researchers suggest the use of interviews as one of the most common methods to evaluate the UX of learning management systems [15]. For quantitative data, a questionnaire consisting of two parts was developed. Part one consisted of demographic information while part two consisted of 29 questions, one question for each of the UX sub-categories. The online questionnaire was sent to the students of the School of Computing at the UTM University via Email, WhatsApp and Telegram applications. The students were asked to answer the questions of the questionnaire to reflect their experience toward the Moodle e-learning system. The aim of the research, its benefits and the instructions to fillout the questionnaire were explained in the first page of the questionnaire. Regarding the second part of the questionnaire, the students were asked to rate their agreement on each of the 29 statements using a seven-point Likert scale.

After this, the semi-structured interviews were conducted as a follow-up process to clarify the issues raised in the questionnaire and to identify students' UX problems qualitatively regarding their UX of the Moodle e-learning system. Advertisements to call for participants were sent to the students of the School of Computing at the UTM University via email, WhatsApp and Telegram applications. In each interview session, the students were asked to reflect their experience with Moodle e-learning system in terms of the identified UX categories and their corresponding subcategories. Also, the students were asked to provide additional challenges they face while interacting with the current elearning system. Furthermore, the students were asked to provide suggested improvements to the Moodle e-learning system to improve the learning process. An honorarium of RM30 was given to each student who participated in the interview sessions.

TABLE I. CATEGORIES AND SUB-CATEGORIES OF THE SUGGESTED UX CRITERIA ADAPTED FROM MTEBE AND KISSAK [5] AND TOPOLEWSKI ET AL. [22]

\begin{tabular}{|l|l|}
\hline UX Category & UX Sub-category \\
\hline $\begin{array}{l}\text { Teaching and } \\
\text { Learning }\end{array}$ & $\begin{array}{l}\text { Instructional materials; collaborative learning; learner } \\
\text { control; feedback and assessment; accessibility; } \\
\text { motivation to learn }\end{array}$ \\
\hline Economical & Entertaining; pleasantness; productivity; usefulness \\
\hline Technological & Novelty; efficiency; reliability; user-friendliness \\
\hline Emotional & Attractiveness; enjoyment; fulfilment \\
\hline Cognitive & Comprehensiveness; engagement; meaningfulness \\
\hline Interpersonal & Communicativeness; confidence \\
\hline Emphatical & $\begin{array}{l}\text { Attentiveness; helpfulness; respectfulness; } \\
\text { responsiveness }\end{array}$ \\
\hline Intention to Use & Convincingness; willingness; recommend \\
\hline
\end{tabular}

TABLE II. A COMPARISON BETWEEN THE SUGGESTED USER EXPERIENCE (UX ) CRITERIA WITH THE OTHER SIMILAR CRITERIA

\begin{tabular}{|l|l|l|l|}
\hline \multirow{2}{*}{$\begin{array}{l}\text { User Experience (UX) } \\
\text { Criteria }\end{array}$} & \multicolumn{3}{|l|}{ User Experience (UX) Metrics } \\
\cline { 2 - 4 } & $\begin{array}{l}\text { Instructional or } \\
\text { didactic metrics }\end{array}$ & $\begin{array}{l}\text { Usability } \\
\text { metrics }\end{array}$ & $\begin{array}{l}\text { Hedonic } \\
\text { metrics }\end{array}$ \\
\hline $\begin{array}{l}\text { UX criteria suggested by } \\
\text { Topolewski } \text { et al. } \text { [22] }\end{array}$ & $\boldsymbol{V}$ & $\checkmark[22]$ & $\checkmark[22]$ \\
\hline $\begin{array}{l}\text { UX criteria suggested by } \\
\text { Mtebe [6] }\end{array}$ & $\checkmark[5]$ & $\checkmark[25]$ & $\checkmark[26]$ \\
\hline $\begin{array}{l}\text { UX criteria suggested by this } \\
\text { research }\end{array}$ & $\checkmark[5]$ & $\checkmark[22]$ & $\checkmark[22]$ \\
\hline
\end{tabular}


The qualitative data were analyzed based on the categories and sub-categories of the suggested UX criteria. The analysis of the qualitative data obtained from the interview sessions resulted in explaining the current UX of the students regarding their use of the Moodle e-learning system, and identified the challenges they faced while interacting with it. These are presented in the Results Section. Descriptive analysis was used for Part 1 of the questionnaire to describe the characteristics of the students; this is presented in the Results Section. Likert scores were calculated for each statement in Part 2 to describe students' responses to the 29 statements. For the purpose of the analysis, a Likert score of 1-3 was regarded as a negative response, 5-7 as a positive response and 4 as a neutral one. The Likert scores for the statements are presented in the Results Section.

\section{RESULTS}

This section presents the results obtained from the analysis of the questionnaires and semi-structured interviews which describe the students' experience with the Moodle e-learning system used at the UTM University. A total of 120 students from the UTM University, School of Computing responded to the questionnaire and a total of 20 students were interviewed in 20 interview sessions. Most of the students who participated in the questionnaire were male $(83 \%)$. Regarding the years of study, the students were in their first $(15 \%)$, second $(36 \%)$, third $(33 \%)$ and fourth $(16 \%)$ years. The majority $(81 \%)$ had one to three years' experience with Moodle, and the majority $(83 \%)$ used Moodle daily. The majority of the students $(91 \%)$ used a laptop and a desktop to access Moodle. Regarding the interview sessions, most of the students who participated were male $(80 \%)$. The majority of them $(80 \%)$ were in the second year of study and had one to three years' experience with Moodle. The average time for the interviews was 35 minutes.

The following presents the students' experience with the elearning system in terms of the identified eight UX categories and their corresponding 29 sub-categories obtained from the analysis of quantitative and qualitative data. The Likert scores for the UX categories and their related sub-categories are presented in Table III.

\section{A. Teaching and Learning}

- Instructional materials: All the students in the interviews stated that the course materials presented on the Moodle e-learning system were current and relevant to them; they supported them in the learning process, which explained the positive Likert score for this sub-category. However, the students suggested some improvements regarding the instructional materials which included:

- Presenting course outlines for the courses before registration.

- Providing access to courses and their materials from the previous semester.

- Presenting exam questions/papers from the previous semester. The students stated that "we need to rely on the seniors or lecturers to get past exam papers because this is not provided on the system".

- Providing course materials during the exam period; the students indicated that most of the lecturers hide them early.

- Collaborative learning: The Likert scores showed that the students were dissatisfied with the e-learning system regarding its lack of support for collaborative learning. The reasons behind this lack of satisfaction were explained in the interviews and the complaints related to: lack of permission to create groups for assignments when most of them needed this because of their group-based assignments; and lack of support for group submissions when most of the assignments were actually group-based.

TABLE III. LIKERT SCORES FOR THE UX SUB-CATEGORIES

\begin{tabular}{|c|c|c|}
\hline UX Category & UX Sub-Category & Likert Scores \\
\hline \multirow{6}{*}{$\begin{array}{l}\text { Teaching and } \\
\text { Learning }\end{array}$} & Instructional materials & 5.1 \\
\hline & Collaborative learning & 3.6 \\
\hline & Learner control & 4.2 \\
\hline & Feedback and assessment & 3.5 \\
\hline & Accessibility & 5.3 \\
\hline & Motivation to learn & 5.5 \\
\hline \multirow{4}{*}{ Economical } & Entertaining & 3.2 \\
\hline & Pleasantness & 3.5 \\
\hline & Productivity & 5.2 \\
\hline & Usefulness & 5.7 \\
\hline \multirow{4}{*}{ Technological } & Novelty & 3.4 \\
\hline & Efficiency & 5.2 \\
\hline & Reliability & 5.3 \\
\hline & User-friendliness & 5.1 \\
\hline \multirow{3}{*}{ Emotional } & Attractiveness & 4.5 \\
\hline & Enjoyment & 4.2 \\
\hline & Fulfilment & 5.1 \\
\hline \multirow{3}{*}{ Cognitive } & Comprehensiveness & 5.3 \\
\hline & Engagement & 4.6 \\
\hline & Meaningfulness & 5.5 \\
\hline \multirow{2}{*}{ Interpersonal } & Communicativeness & 3.7 \\
\hline & Confidence & 4.3 \\
\hline \multirow{4}{*}{ Emphatical } & Attentiveness & 5.3 \\
\hline & Helpfulness & 4.3 \\
\hline & Respectfulness & 5.4 \\
\hline & Responsiveness & 5.6 \\
\hline \multirow{3}{*}{ Intention to Use } & Convincingness & 5.5 \\
\hline & Willingness & 5.2 \\
\hline & Recommend & 5.4 \\
\hline
\end{tabular}


- Learner control: This related to Moodle's support for organizing the e-learning materials into clear and logical units. The Likert scores for this sub-category showed that the students gave a neutral response. The students in the interviews explained the reasons behind this which related to the fact that lecturers could change the layout or the structure of the course page based on their preferences: for example, by weeks in ascending order; by weeks but in descending order, or in the middle of the page. The students stated that when lecturers chose to present the materials of their course by weeks in ascending order, the new material was displayed at the bottom of the page which required the student to scroll down to access it. One student said: "It is not easy to access the new materials when the page is too long." Another student said: "I get tired of keep scrolling down all the time to access the latest materials." Other students stated that some other lecturers would add the new materials to the middle of the page and this confused them a lot.

- Feedback and assessment: The Likert scores showed that the students were dissatisfied with the lack of immediate feedback on their assessments. This was explained by the students in the interviews as they indicated that there was a lack of feedback or comments on the submitted assignments, online quizzes and tests from the lecturers since most of the lecturers did not allow the marks to be viewed. The students stated, "We would suggest making a separate section for displaying our marks." The students also indicated that the system does not support students for sending their feedback.

- Accessibility: The students were satisfied with the fact that the e-learning system is accessible anytime and anywhere through various devices, such as laptops and desktops. This is reflected in the Likert score for this sub-category. However, in the interviews, the students identified some issues related to the mobile application. These related to it not being user friendly; there was also a lack of support for most of the used functions. For this, the students indicated that they preferred to use their laptop or desktop to access Moodle.

- Motivation to learn: The students stated that the Moodle e-learning system motivated them to learn since it supported quick submission of assignments. It also had the ability for assignments to be resubmitted before the due date; the viewing and grading of assignments, if the lecturer chose to present them, was enabled; online quizzes and tests could be conducted easily and students could be informed of their quizzes' and/or tests' marks instantly (if the lecturer allowed the marks to be viewed). This was in accordance with the positive Likert score related to this sub-category.

\section{B. Economical}

- Entertaining: The students in the interviews indicated that the Moodle e-learning system did not entertain them. This is in accordance with the negative Likert score related to this sub-category.
- Pleasantness: The students in the interviews stated that the current e-learning system was not pleasant to use; they have to use it as part of the learning process. This is in accordance with the negative Likert score related to this sub-category.

- Productivity: The Likert score related to this subcategory indicated that the Moodle e-learning system helped the students to be more productive. The students in the interview explained the reasons behind this which related to the fact Moodle presents all the instructional materials in one place which is easy to access and easy to use. Also, it supports the easy submission of assignments; also, quizzes and tests can be conducted easily and knowledge of the grades achieved is prompt if lecturers are using the grading system.

- Usefulness: The students perceived the Moodle elearning system to be useful. It allows them to carry out their typical tasks, such as downloading materials and submitting assignments, with ease. This is in accordance with the positive Likert score related to this sub-category. However, the students indicated that the usefulness could be improved if Moodle could:

- Be used to support communication with their lecturers instead of using other applications such as Telegram or WhatsApp;

- Support online video meetings so that the students do not have to use other applications to meet their lecturers.

\section{Technologica}

- Novelty: The students stated that they did not consider the Moodle e-learning system as novel or new to them. This was reflected in the negative Likert score for this sub-category.

- Efficiency: The students considered the e-learning system to be efficient, allowing them to be efficient while learning; this is reflected in the positive Likert score for this sub-category. However, most of the students indicated that the efficiency of the e-learning system is based on how the lecturers use it in terms of the functions they provide for their students. They cited examples such as: the layout they chose for the course page; the communication methods they used to communicate with their students; the relevant use of the advertisement section to announce news; and the announcement of gradings for assignments and quizzes. The students suggested adding an internal search function to the current e-learning system to improve its efficiency.

- Reliability: The Likert score showed that the students perceived the Moodle e-learning system as reliable. The students in the interviews also indicated that the elearning system is, in general, reliable. However, there were some issues which affected its reliability: for example, it was unable to handle high volumes of traffic during exams and assignment deadlines, which 
resulted in the system breaking down. Also, the students indicated that sometimes there were login errors. Furthermore, the system did not display an appropriate error message when uploading a large file which exceeded the permitted size; instead, the system stopped responding.

- User-friendliness: The students indicated that the elearning system was easy to use in terms of: it was easy to login, to navigate, to submit assignments, to access lecture materials, to download documents and files, and to go through online quizzes and tests. This is in accordance with the positive Likert score related to this sub-category. Furthermore, most of the students were satisfied with the interface design of the system which included: the interface was not cluttered, information was clearly displayed, and the fonts and colours were appropriate and clear to read. However, the students indicated that the system is not easy for computer illiterates, such as first-year students. The students also identified the following issues which related to the user-friendliness of the Moodle e-learning system:

- Lack of color customization: the students could not change the colour of the Moodle pages.

- Inappropriate design of the "Mark As Done" button which is used to keep track of the progress of each task. The students indicated that its size is too big which affects the length of the page.

- Inappropriate color for the "Mark As Done" button. The students indicated that this button should be either green or red to attract the attention of the students.

\section{Emotional}

- Attractiveness: The Likert score related to this subcategory was neutral; the students in the interview indicated that they did not find the Moodle e-learning system attractive. They stated that the Moodle interface is poor and still needs several improvements in certain aspects.

- Enjoyment: The students stated that Moodle e-learning system is not enjoyable. The Likert score for this subcategory was neutral.

- Fulfilment: The positive Likert score related to this sub-category indicated that the students perceived the Moodle e-learning system as a fulfilling one. The students in the interview indicated that the e-learning system allowed them to achieve appropriately the required learning tasks, including downloading the required materials, submitting assignments and going through online tests and/or quizzes. However, the students mentioned some issues related to this subcategory which needed to be improved:

○ The permitted file size to be uploaded was small;

- It took time to upload large files.

\section{E. Cognitive}

- Comprehensiveness: The students indicated that the current e-learning system is comprehensive since the instructional materials which were provided for most of the courses were sufficient and helpful; this is in accordance with the positive Likert score related to this sub-category. However, the students stated that the comprehensiveness of the e-learning system is mainly based on individual lecturers in terms of the content they added to the system and the functions they used to support the learning process.

- Engagement: The Likert score related to this subcategory was neutral and the students in the interviews indicated that Moodle did not allow them to engage in their tasks.

- Meaningfulness: The students indicated that the current e-learning system was meaningful and supported the learning process; this is in accordance with the positive Likert score related to this sub-category. However, the students stressed that the meaningfulness of the Moodle e-learning system was based on the functions and options lecturers used to manage their courses.

\section{F. Interpersonal}

- Communicativeness: The negative Likert score related to this sub-category indicates the students' dissatisfaction with the current communication support provided by Moodle. The students in the interviews stated that there is lack of communication options between students and lecturers offered by the system. Therefore, the students and lecturers used other communication channels, such as Telegram, to communicate with each other. The students indicated that they preferred to use Moodle to support their communication with their lecturers instead of using other applications.

- Confidence: The students indicated that the current Moodle e-learning system did not allow them to trust others; the Likert score for this sub-category was neutral.

\section{G. Emphatical}

- Attentiveness: The students indicated that the elearning system allowed them to be attentive. For example, the students were satisfied with the availability of the constant reminder for the submission of assignments before the deadline. However, the students suggested improvements to the current elearning system in terms of:

○ The system should support sending a notification to their email when a lecturer uploads new assignments or new materials, or makes any update to the course.

- The Announcement forum should be used properly to notify them of any announcement, such as a public holiday or other important dates. 
- Helpfulness: The students indicated that the current Moodle e-learning system did not allow them to help others because of the lack of supporting communications among students. The Likert score related to this sub-category was neutral.

- Respectfulness: The students believed that the current e-learning system allowed them to be respectful to their lecturers' deadlines for submitting assignments since it provided them with reminders to submit the assignment before the deadline. This is in accordance with the positive Likert score related to this subcategory.

- Responsiveness: The positive Likert score related to this sub-category showed that the students perceived the Moodle e-learning system to be responsive. The students in the interviews stated that, in general, the elearning system allowed them to be responsive despite the fact that this is mainly based on the lecturers' choice of features they use in Moodle and the content they add to it. Specifically, the students stated that the e-learning system supported them to be responsive in terms of:

- Submitting assignments before the deadline because of the constant reminders sent by the system to their emails;

- Responding or taking action regarding the announcements for specific events (in the courses where lecturer used it);

- Improving their performance since the system gives them their marks immediately after online tests and quizzes (in the courses where the lecturer activates this functionality);

○ Improving their knowledge when lecturers added additional motivating content for some courses.

\section{H. Intention to Use}

- Convincingness: Most of the students stated that they were convinced to continue using the Moodle elearning system as it included all the functions they needed. However, they suggested that the Moodle elearning system would offer more benefits if lecturers were able to use most of the available functions the system provided. The Likert score related to this subcategory was positive which stressed the fact that students were convinced of the use of the e-learning system.

- Willingness: The positive Likert score related to this sub-category indicates that the students were willing to re-use the Moodle e-learning system. The students in the interviews indicated that they were willing to re-use Moodle until they graduated from the university as it supported their needs.

- Recommend: The students stated that they could recommend using the Moodle e-learning system in other universities but they suggested that it would be more beneficial if most of the functions provided by
Moodle were used by the lecturers and students to support the learning process. The positive Likert score related to this sub-category stressed students' recommendation to use the Moodle e-learning system in other universities.

\section{DISCUSSION}

This research addressed the gap identified in the literature regarding the lack of a specific UX technique or UX criteria that could be used to evaluate the UX of e-learning systems and the lack of research which investigated User Experience (UX) of e-learning systems. This research suggested evaluation criteria to evaluate the UX of e-learning systems; these were adopted from two reliable methods [5, 22]. The suggested criteria included instructional or didactic metrics, and usability and hedonic metrics; thus, these can be used to evaluate comprehensively the UX of an e-learning system. Based on the suggested criteria, this research investigated the UX of the Moodle e-learning system employed at the University of Technology Malaysia (UTM) from the perspectives of students.

The results showed that the students in general had a positive User Experience (UX) of the Moodle e-learning system. However, they identified several issues which affected their experience when interacting with system. It is worth mentioning that most of the issues that were identified were based on the lecturers' use of Moodle's functions. These findings are in accordance with the findings of earlier research which also showed that the e-learning systems had several UX problems related to instructors' skills and usage, and the course content and structure managed by the instructors [6, $10]$.

Specifically, and with regard to the instructional, usability and hedonic metrics, the results showed that the students were satisfied with the quality of the instructional materials presented on the e-learning system in terms of them being current, relevant and supportive to the students' learning. These results opposed those obtained from earlier research which showed that the students were dissatisfied with the presence of outdated instructional materials or the unavailability of instructional materials [6].

The results also showed that the students were satisfied with the accessibility of the Moodle e-learning system; they also considered the system to be a good motivator for them to learn since it supported most of the functions they needed. However, the students also identified some issues which could be improved regarding the instructional metrics. These included: a lack of availability of previous semester exam papers; lack of support for collaborative learning; unclear organization of the course page; lack of feedback on the assignments, quizzes and tests from the lecturers; and the unusable mobile application. There were similarities between these results and the results of earlier research in terms of the identification of inconsistent layout or structure of the instructional materials which differed from one course to another based on the lecturers' preference; a lack of support for group work; server break downs; lack of customization; and the lack of an effective mobile application $[6,10]$. 
Regarding the usability metrics, the results showed that the students were satisfied with the usability of the Moodle elearning system on both laptop and desktop devices; this is in accordance with the results obtained from Maslov et al.'s research [10]. However, the students identified some minor issues or usability problems on Moodle's interface which could be improved. The students also indicated that the usability of the Moodle e-learning system was based on the level of experience of the person using it; thus, the more the students used the system, the more usable it became. These results are also similar to the results obtained from earlier research which found that Moodle for some students was a hard platform to use but one which became easier over time and experience $[10,21]$.

Regarding the hedonic metrics, the results showed thar the students were satisfied with their experience while using the Moodle e-learning system; specifically, they indicated that they perceived Moodle as productive, useful, efficient, reliable, fulfilling, comprehensive and meaningful. They noted that it supported students to be attentive, respectful and responsible to others. The results also showed that the students were convinced of the use of the Moodle e-learning system. They were willing to re-use it and would recommend other universities to use it because of its benefits in supporting the learning process. These results are similar to those found in other research studies regarding the positive feelings and memories that Moodle provides to students [6]. However, the students indicated that the Moodle e-learning system is not entertaining, pleasant or novel, and it did not support communications with their lecturers. These results are similar to those of Maslov et al.'s study [10]. Also, the students were neutral regarding the attractiveness, enjoyment, engagement, confidence and help of the Moodle e-learning system. These results are also in accordance with earlier research results which showed that students were neutral regarding interesting or exciting functionalities offered by Moodle [6].

The results of this research suggest that each university or academic institution which employs an e-learning system should provide a comprehensive course for their staff to explain the wide-ranging functionalities supported by the elearning system in order to improve their skills and knowledge regarding these functionalities. This will then help lecturers to use the e-learning system more effectively by employing most of the functionalities to support the learning process, thus improving the students' experience while using the e-learning system.

The results of this research can be used to improve the user experience (UX) at the case study university (UTM) and can also be used in general to improve the user experience of Moodle e-learning systems by considering the challenges the students face when interacting with such a system.

\section{CONCLUSIONS}

This research examined the user experience (UX) of the Moodle e-learning system employed at the University of Technology Malaysia (UTM) from students' perspectives using comprehensive user experience (UX) criteria adopted from two criteria. The adopted UX criteria consist of teaching and learning, usability and hedonic metrics; these related to 8 categories and 29 corresponding sub-categories. Two methods were employed to investigate the UX of the e-learning system: semi-structured interviews and questionnaires. These were employed based on the UX criteria. A total of 20 students participated in the interviews and a total of 120 students responded to the questionnaires. The results showed that the students were satisfied with the e-learning system and they had positive user experiences while interacting with it through their learning. However, several issues relating to aspects of the UX criteria were identified by the students; these need to be considered in order to improve the UX of the e-learning system.

This research contributes to the literature regarding the suggested UX criteria which were adopted to investigate user experience (UX) of an e-learning system; it also contributes to the literature regarding the results which identified several challenges to the Moodle e-learning system which affected the experience of users (UX). However, there are some research limitations related to this study. The first relates to the fact that the study used only students to evaluate the user experience (UX) of the e-learning system. Other users, including lecturers, were not considered. The second limitation relates to the fact that the reliability of the suggested user experience (UX) criteria has not yet been tested.

Future research can be conducted to evaluate the user experience (UX) of Moodle e-learning system used by the University of Technology Malaysia (UTM) from lecturers' perspectives. Also, further research can be conducted to test and validate the reliability of the suggested user experience (UX) criteria employed in this research.

\section{REFERENCES}

[1] H. E. D. Amandi, and W. R. M. S. Shanika, "The student perspective on usability of learning management system at university of Sri Jayewardenepura," 18th FMSC Research Sessions, 2021.

[2] S. Bermejo, "Cooperative electronic learning in virtual laboratories through forums," IEEE Transactions on Education, vol. 48, no. 1, pp. 140-149, 2005.

[3] Syngene Research, Global e-learning market analysis 2019, 2019. https://www.researchandmarkets.com/reports/4769385/global-elearning-market-analysis-2019.

[4] M. Simonson, "Course management systems", Quarterly Review of Distance Education, vol. 8, no. 1, vii-ix, 2007.

[5] J.S. Mtebe, and M.M. Kissaka,"Heuristics for evaluating usability of learning management systems in Africa", in Cunningham, P. and Cunningham, M. (Eds), IST - Africa 2015, Conference Proceedings, Lilongwe, pp. 1-13, 2015.

[6] S. J. Mtebe, "Examining user experience of eLearning systems implemented in two universities in Tanzania", Interactive Technology and Smart Education, vol. 17, no. 1, , pp. 39-55, 2020.

[7] L. Hasan, "The usefulness and usability of Moodle LMS as employed by Zarqa University in Jordan ", Journal of Information Systems and Technology Management (JISTEM), vol. 16, 2019.

[8] D. Ivanc, R. Vasiu, and M. Onita, "Usability evaluation of a LMS mobile web interface", in the Proceedings of the 18th International Conference, ICIST 2012, Kaunas, Lithuania, September 13-14, 2012, pp. 348-361, 2012.

[9] Moodle, <https://moodle.org/>, [accessed 01.08.2021].

[10] I. Maslov, S. Nikou, and P. Hansen, "Exploring user experience of learning management system", The International Journal of Information and Learning Technology, vol. 38, no. 4, pp. 344-363, 2021.

[11] ISO 9241-210:2010, "Ergonomics of human-system interaction - part 210: human-centred design for interactive systems", 2010. 
[12] ISO 9241-11, "International standard first edition. ergonomic requirements for office work with visual display terminals (vdts), Part11: guidance on usability”, 1998.

[13] N. Bevan, "Classifying and selecting UX and usability measures", International Workshop on Meaningful Measures: Valid Useful UX Measurement, vol. 11, pp. 13-18, 2008.

[14] M. Hassenzahl, and N. Tractinsky, "UX-a research agenda", Behaviour and Information Technology, vol. 25, no. 2, pp. 91-97, 2006.

[15] W. T. Nakamura, E. H. T. de Oliveira, and T. Conte, "Usability and user experience evaluation of learning management systems - a systematic mapping study", In Proceedings of the 19th International Conference on Enterprise Information Systems (ICEIS 2017), pp. 97-108, 2017.

[16] W. Nakamura, L. Marques, L. Rivero, E. Oliveira, and T. Conte, "Are generic ux evaluation techniques enough? a study on the ux evaluation of the edmodo learning management system", Brazilian Symposium on Computers in Education (SBIE), vol. 28, no. 1, pp. 1007-1016, 2017.

[17] I. Santoso, and I. Efendy, "Usability study of Moodle LMS in statistics Indonesia learning center - case study," International Conference on Science Education and Technology, Journal of Physics: Conference Series, IOP Publishing vol. 1511, 2020.

[18] M. E. Eltahir, S. Al-Qatawneh, N. Al-Ramahi, and N.Alsalhi, "The perspective of students and faculty members on the efficiency and usability of e-learning courses at Ajman University: A case study," Journal of Technology and Science Education, vol. 9, no. 3, pp. 388403, 2019.

[19] N. Harrati, I.Bouchrika, A. Tari, and A. Ladjailia, "Exploring user satisfaction for e-learning systems via usage-based metrics and system usability scale analysis," Computers in Human Behavior, vol. 61, pp. 463-47, 2016.

[20] J. Melton, "The LMS Moodle: a usability evaluation," Languages Issue, vol. 11/12, no. 1, pp. 1-24, 2006.

[21] 1. Senol, H. Gecili, and P. Durdu, "Usability evaluation of a Moodle based learning management system," in the Proceedings of EdMedia 201, Tampere, Finland, June 23-26, 2014.

[22] M.Topolewski, H. Lehtosaari, P. Krawczyk, M. Pallot, I. Maslov, and J. Huotari, "Validating a UX model through a formative approach: an empirical study", 2019 IEEE International Conference on Engineering, Technology and Innovation (ICE/ITMC), IEEE, pp. 1-7, 2019.

[23] V. Roto, H. Rantavuo, and V.V.M. Kaisa, “Evaluating user experience of early product concepts", International Conference on Designing Pleasurable Products and Interfaces, pp. 1-10, 2009.

[24] L. Shi, "Defining and evaluating learner experience for social adaptive E-Learning", The 4th Imperial College Computing Student Workshop (ICCSW 2014), pp. 25-26, 2014.

[25] J. Nielsen, "Heuristic evaluation", in N. Jakob, and R.L. Mack (Eds), Usability Inspection Methods, John Wiley and Sons, New York, NY, 1994.

[26] M. Hassenzahl, “"The thing and I: Understanding the relationship between user and Product"', in M. Blythe, C. Overbeeke, A. Monk, and P.S.N. Wright (Eds), Funology: From Usability to Enjoyment, Kluwer Academic Publishers, Norwell, MA, pp. 31-42, 2005.

APPENDIX I. CATEGORIES, SUB-CATEGORIES AND DESCRIPTION OF THE SUGGESTED UX CRITERIA ADAPTED FROM MTEBE AND KISSAK [5] AND TOPOLEWSKI ET AL. [22]

\begin{tabular}{|l|l|l|}
\hline UX Category & UX Sub-category & Description \\
\hline & $\begin{array}{l}\text { Instructional } \\
\text { materials }\end{array}$ & $\begin{array}{l}\text { Degree to which Moodle consists of } \\
\text { relevant learning materials (such as } \\
\text { whether they are accurate, current). }\end{array}$ \\
\cline { 2 - 3 } $\begin{array}{l}\text { Teaching and } \\
\text { Learning }\end{array}$ & $\begin{array}{l}\text { Degree to which Moodle has } \\
\text { facilities and activities that } \\
\text { encourage inter- and intra-group } \\
\text { activities such as group projects, } \\
\text { group debates, discussions, } \\
\text { collaborative problem solving and } \\
\text { presentations. }\end{array}$ \\
\hline
\end{tabular}

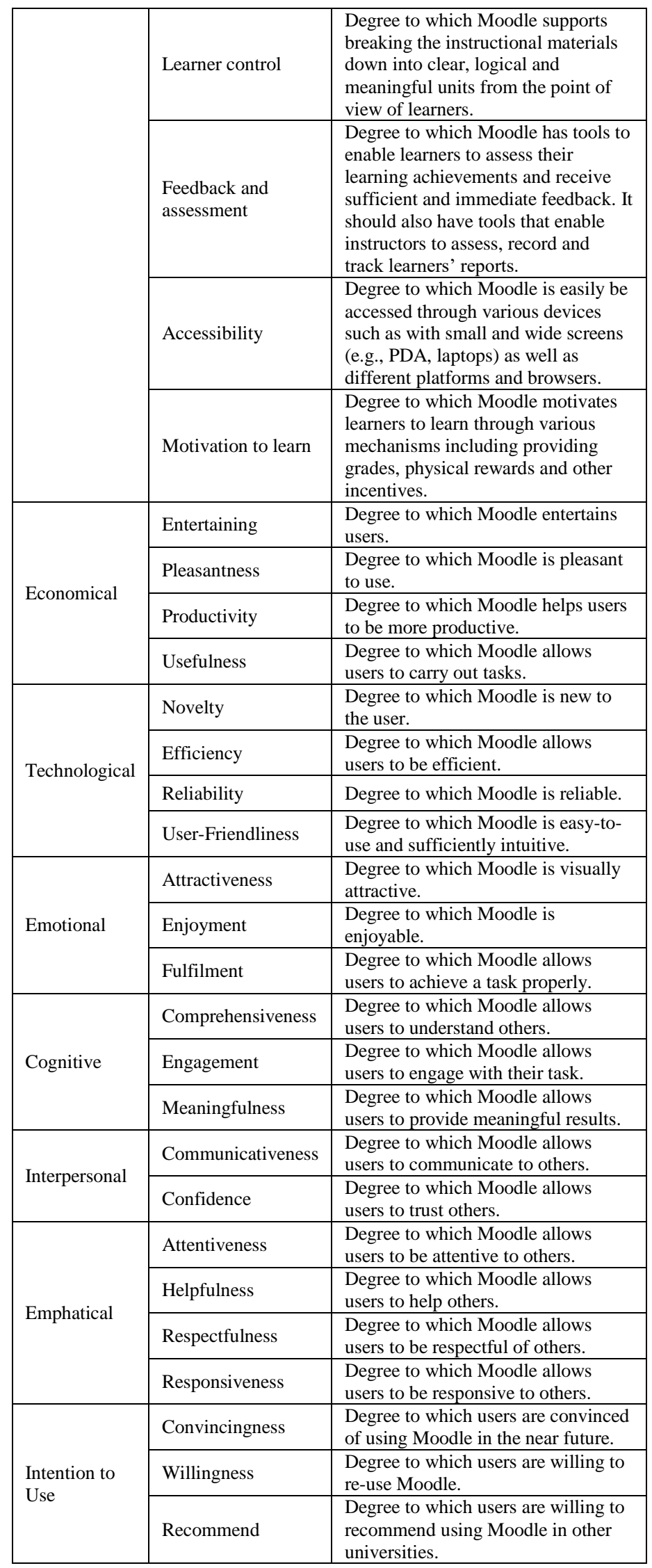

